\title{
Holistic approach to prevention and management of type 2 diabetes mellitus in a family setting
}

This article was published in the following Dove Press journal:

Diabetes, Metabolic Syndrome and Obesity: Targets and Therapy

23 May 2014

Number of times this article has been viewed

\section{Sandra N Ofori Chioma N Unachukwu \\ Department of Internal Medicine, University of Port Harcourt Teaching Hospital, Port Harcourt, Rivers State, Nigeria}

Correspondence: SN Ofori Department of Internal Medicine, University of Port Harcourt Teaching Hospital, PMB 6173, Choba, Rivers State, Nigeria Tel +2348096598508 Email sandytom77@yahoo.com

\begin{abstract}
Diabetes mellitus (DM) is a chronic, progressive metabolic disorder with several complications that affect virtually all the systems in the human body. Type 2 DM (T2DM) is a major risk factor for cardiovascular disease (CVD). The management of T2DM is multifactorial, taking into account other major modifiable risk factors, like obesity, physical inactivity, smoking, blood pressure, and dyslipidemia. A multidisciplinary team is essential to maximize the care of individuals with DM. DM self-management education and patient-centered care are the cornerstones of management in addition to effective lifestyle strategies and pharmacotherapy with individualization of glycemic goals. Robust evidence supports the effectiveness of this approach when implemented. Individuals with DM and their family members usually share a common lifestyle that, not only predisposes the non-DM members to developing DM but also, increases their collective risk for CVD. In treating DM, involvement of the entire family, not only improves the care of the DM individual but also, helps to prevent the risk of developing DM in the family members.
\end{abstract}

Keywords: cardiovascular disease, multifactorial management

\section{Introduction}

Diabetes mellitus (DM) is a chronic, progressive metabolic disorder characterized by hyperglycemia with long-term microvascular (retinopathy, nephropathy, and neuropathy) and macrovascular (cardiovascular) complications. It is classified into four types, and type 2 DM (T2DM) is the predominant type, accounting for about $90 \%$ of all cases. ${ }^{1}$ Peripheral resistance to insulin and pancreatic beta-cell dysfunction characterizes it. The beta-cell dysfunction, which is accelerated by chronic hyperglycemia, is primarily responsible for its progression. ${ }^{2}$

The prevalence of T2DM is rising worldwide. In 2011, the global estimate was 336 million people living with T2DM. This has been projected to increase to 552 million by 2030 . In Nigeria, the prevalence of DM in 2010 was $4.7 \%$, and this has been projected to increase to $5.5 \%$ by $2030 .{ }^{3}$ Similarly, in the UK, the prevalence is expected to increase from 2.9 million affected in 2011 to five million by $2025 .{ }^{1}$ In 2009, the treatment of DM and its complications cost the UK National Health Service (NHS) $£ 1$ million per hour. This translates to $£ 9$ billion a year, which is nearly $10 \%$ of its annual budget. ${ }^{1}$ In developing countries with poorer health care systems, the cost of managing DM is considerable. In a recent randomized, controlled trial (RCT) in Nigeria, Adibe et al showed that pharmaceutical intervention with a multidisciplinary approach cost 88,525 Nigerian naira (571 US dollars) per quality-adjusted life years gained. ${ }^{4}$ Although this was $95 \%$ more cost effective compared with usual care 
(incremental cost of 10,623 Nigerian naira or 69 US dollars), it still represents a significant financial burden in a country where $68 \%$ of the population live below the international poverty line of 1.25 US dollars per day. ${ }^{5}$

$\mathrm{DM}$ is a major risk factor for cardiovascular disease (CVD), and a DM individual is two to four times more likely to develop CVD compared with a non-DM individual. ${ }^{6}$ In turn, CVD accounts for about $50 \%$ of the mortality in the DM population. ${ }^{7}$ In Africa, of all the common chronic noncommunicable diseases, DM is said to have the highest morbidity and mortality rates. ${ }^{8}$ Individuals with DM and their family members usually share a common lifestyle that, not only predisposes the non-DM members to developing DM but also, increases their collective risk for CVD. In managing DM, therefore, it is imperative that the family members be involved in the care of the affected individual as well as receive an evaluation for their risk of developing DM. Management interventions can then include efforts to mitigate this risk.

The aim of this review was to discuss the evidence-based lifestyle strategies and multifactorial medical management approaches that can be implemented in any family with DM members to reduce the risk of developing DM and prevent or delay onset of complications in those who already have DM.

\section{Risk factors}

There are several factors that increase the risk of developing T2DM, some of which include: ${ }^{9}$

- Obesity

- Ethnicity (nonwhite ancestry eg, African American, Native American, Asian American, Pacific Islander, and South Asian)

- Low birth weight

- Family history of DM in a first-degree relative

- Increasing age

- Polycystic ovarian syndrome

- Physical inactivity

- Low-fiber, high-fat, energy-dense diet

- Urbanization

- Signs of insulin resistance, such as acanthosis nigricans

- CVD/hypertension

- Impaired glucose regulation

- Gestational DM (GDM)

Having a first-degree relative with DM is a strong risk factor. In women, GDM increases the chances of developing T2DM by sevenfold. ${ }^{10}$ Forty percent of women who develop GDM in pregnancy will develop DM within 5 years, especially with increasing age. DM represents one end of the spectrum of abnormal glucose metabolism that is preceded by impaired glucose regulation, which encompasses impaired fasting glucose $(6.1-6.9 \mathrm{mmol} / \mathrm{L})$, impaired glucose tolerance (7.8-11.1 mmol/L 2 hours after a $75 \mathrm{~g}$ oral glucose tolerance test [OGTT]) and glycated hemoglobin $\left(\mathrm{HbA}_{1 \mathrm{c}}\right)$ between $5.7 \%-6.4 \%{ }^{11}$ Lifestyle-related risk factors, like a sedentary lifestyle and increased consumption $(>1 /$ day $)$ of sugary beverages, almost doubles the risk of DM. ${ }^{11}$ Lifestyle risk factors also contribute to obesity, a key risk factor for developing DM, especially when the weight is gained in early adulthood between 25 and 40 years of age. ${ }^{12}$ Obesity is associated with increased insulin resistance and hypertension and is also a major CVD risk factor. A systematic review of ten cohort studies showed that moderate-intensity, regular physical activity reduced the risk of DM by about $31 \%$ compared with being sedentary. ${ }^{13}$

\section{Clinical management strategies}

The management of T2DM is multifactorial, taking into account other major modifiable risk factors, like obesity, physical inactivity, smoking, blood pressure (BP), and dyslipidemia. A multidisciplinary team is essential to maximize the care of DM patients, and the members of such a team are as outlined in Table 1.

The evidence-based strategies for DM management include:

- Lifestyle-related strategies (nutrition therapy and physical activity)

- Medical management (pharmacotherapy) with ongoing evaluations for the onset of complications.

These are carried out within the context of patientcentered care involving DM self-management and patient education.

\section{Patient-centered care}

A vital component of DM management that should be addressed at the initial consultation with a DM patient and his/her family members is DM self-management education (DSME). This is an ongoing process of facilitating knowledge, skill, and abilities necessary for DM self-care. ${ }^{14} \mathrm{It}$ covers the following key areas: the disease process, treatment options, nutritional and exercise plan, knowledge of prescribed medication, self-monitoring of blood glucose, knowledge of acute and chronic complications, and psychosocial issues. ${ }^{15}$ It is effective in reducing $\mathrm{HbA}_{1 \mathrm{c}}$ by $0.8 \%$, at least in the short term, as demonstrated in one meta-analysis. ${ }^{16}$ Additionally, structured group education offered to patients 
Table I Professionals involved and recommended targets for lifestyle and medical risk factors

\begin{tabular}{|c|c|}
\hline Professionals involved in the care & Recommended goals of therapy* \\
\hline Short-term management & Lifestyle goals ${ }^{62}$ \\
\hline Involved in core care, provide support and structured education & Smoking cessation \\
\hline for patients & Weight loss achieved with \\
\hline - Primary care physician & a) Diet \\
\hline - Diabetes specialist nurse & - Calorie restriction to I,500 kcal/day \\
\hline - Certified diabetes educator & - Fat intake restricted to $30 \%-35 \%$ of total daily energy uptake, \\
\hline - Dietitian & with saturated fat $<10.7 \%$ \\
\hline - Physical activity specialist & - $10 \%$ monounsaturated fatty acids, eg, olive oil \\
\hline Long-term management & - Avoidance of trans-fats \\
\hline - Endocrinologist & - Fiber intake restricted to $30 \mathrm{~g}$ per day \\
\hline - Ophthalmologist & b) Physical activity \\
\hline - Podiatrist & - $2.5-5 \mathrm{~h} /$ week moderate-intensity physical activity or \\
\hline - Renal and cardiac physicians & I-2.5 h/week vigorous-intensity exercise \\
\hline - Mental health practitioners & - Limit total time spent being sedentary \\
\hline - Pharmacists & Pharmacotherapy" \\
\hline \multirow[t]{10}{*}{ - Social workers } & Glycemic control (individualized) \\
\hline & - $\mathrm{HbA}_{\mathrm{Ic}}<7 \%$ \\
\hline & - Fasting plasma glucose $3.9-7.2 \mathrm{mmol} / \mathrm{L}$ \\
\hline & - Postprandial glucose $<10 \mathrm{mmol} / \mathrm{L}$ \\
\hline & Lipids \\
\hline & - Total cholesterol $<4 \mathrm{mmol} / \mathrm{L}$ \\
\hline & - $\mathrm{LDL}$ cholesterol $<2.6 \mathrm{mmol} / \mathrm{L}(<\mathrm{l} .8$ if CVD) \\
\hline & - $\mathrm{HDL}$ cholesterol $>1.04 \mathrm{mmol} / \mathrm{L}$ (males), $>1.3$ (females) \\
\hline & - Triglycerides $<1.7 \mathrm{mmol} / \mathrm{L}$ \\
\hline & - $\mathrm{BP}<\mathrm{I} 30 / 80 \mathrm{mmHg}$ \\
\hline
\end{tabular}

Note: *These targets should be individualized, as discussed in the text.

Abbreviations: BP, blood pressure; CVD, cardiovascular disease; $\mathrm{HbA}_{\mathrm{Ic}}$, glycated hemoglobin; HDL, high-density lipoprotein; LDL, low-density lipoprotein.

with newly diagnosed T2DM in a multicenter, cluster $\mathrm{RCT}$ resulted in significant improvements in weight loss, smoking cessation, and positive improvements in beliefs about illness. ${ }^{17}$

DM management requires lifelong adjustments to lifestyle and pharmacotherapy; thus, in order to achieve glycemic and other therapeutic targets (Table 1), active participation and commitment of the individual is essential. Patient preferences, values, objectives, and priorities should be respected, and these should then guide the shared clinical decisionmaking process. This is the patient-centered approach to DM management that is advocated by the American Diabetes Association and European Association for the Study of Diabetes. ${ }^{14}$ It encourages the individuals to "own" their lifestyle goals and action plans.

\section{Evidence-based lifestyle strategies}

Lifestyle modification requires behavior change, therefore, counseling is necessary. This should employ evidence-based behavior change techniques, such as cognitive behavioral therapy and motivational interviewing. ${ }^{18}$ This is necessary in order to explore the health beliefs of the individual; and to identify and overcome any barriers to change, and with them, prioritize the risk factors they wish to address, while increasing their confidence and self-efficacy. Sustainable change has to involve the DM individual and their whole family, including any children, especially in situations where the mother had GDM. Children of mothers with GDM are at risk for obesity and earlier onset of T2DM. ${ }^{19}$

RCTs conducted in the Finnish and Indian populations have demonstrated the effectiveness of lifestyle intervention in preventing T2DM among individuals at risk of developing T2DM. ${ }^{20,21}$ The US Diabetes Prevention Program (DPP) was a larger trial and compared the effectiveness of lifestyle intervention or metformin in delaying or preventing the onset of T2DM. ${ }^{22}$ The 3,234 participants were at high risk for T2DM, mostly female, Caucasian, and had an average age of 51 years and mean body mass index (BMI) of $34 \mathrm{~kg} / \mathrm{m}^{2}$. They were randomly assigned to placebo, metformin ( $850 \mathrm{mg}$ twice daily), or a lifestyle-modification program, respectively, and followed up for 2.8 years. The lifestyle modification involved a healthy, low-calorie, low-fat diet and moderate physical activity, such as brisk walking for at least 150 minutes per week, in order to achieve and maintain a weight reduction of at least $7 \%$. They were supported in achieving these goals by an intensive 16-lesson curriculum promoting dietary education, exercise, 
and behavior modification. Key findings included a 58\% and $31 \%$ relative reduction in the incidence of T2DM in the lifestyle and metformin groups, respectively compared with placebo. This beneficial effect of lifestyle modification was still significant at 10 -year follow up after the end of the trial. ${ }^{23}$

Despite the intensive efforts employed in this trial and the unavoidable bias inherent in having motivated patients enrolling into clinical trials, only $50 \%$ and $74 \%$ of the lifestyle group achieved the weight loss and physical activity targets, respectively, at the end of the 24-week curriculum. Nevertheless, the evidence is robust, and a similar strategy should be employed in managing the family members of a DM individual as they are at risk of developing T2DM. The ideal framework within which to achieve this would be in a primary care/community setting, where the general practitioner has access to, not only the DM individual but also, their family members. Establishing a collaborative relationship between the health care professionals and the adult family members of a DM individual is vital.

The individuals at risk require a risk assessment with an OGTT or $\mathrm{HbA}_{1 \mathrm{c}}$ to screen for DM. ${ }^{24}$ Subsequent assessments for DM should be carried out every 3 years, at least, and females who have a history of GDM should receive family planning advice in order to be adequately prepared prior to any future pregnancies. ${ }^{19}$ All involved health professionals should deliver a clear, consistent educational message on prevention. The general advice should largely focus on the need to adopt a healthy lifestyle tackling overweight, obesity, and physical inactivity, to prevent DM and reduce the risk of its long-term complications. Although the DPP trial was not set up a priori to determine the effects of each of the lifestyle components on DM risk, the subgroup analysis showed weight loss (adjusted for diet and exercise) to be the dominant predictor for reduced DM risk, and exercise sustained the weight loss. ${ }^{25}$ The priority for any overweight first-degree relatives should thus be weight loss. They should be educated on the DPP research that shows that DM onset can be prevented or delayed by at least 4 years by losing $5 \%$ to $7 \%$ of their current body weight. However, any weight loss goals should be realistic and achievable.

A dietician is required, to administer a dietary assessment with available tools, such as a food diary or 7-day dietary recall. This is done in order to help set simple, measurable, achievable, realistic, and time-bound (SMART) dietary goals. The key principles include calorie restriction, low-fat diet, portion control, and increasing fruit, vegetable, and fiber intake. As a whole, the family's eating behavior should be assessed and if necessary, should be modified to encourage regular meal times and healthy eating habits. Prior to commencing physical activity, individuals should be evalu- ated to ensure that any exercise prescription is developed according to their goals and limitations. The recommended exercise goal of at least 150 minutes per week of moderateintensity physical activity translates into 30 minutes a day of activities like brisk walking, or domestic chores in 10-minute bouts, and does not necessarily require a specialized exercise program. Where available, individuals can be offered the option of a structured weight loss program.

Even among individuals already affected by DM, lifestyle changes are beneficial in improving metabolic control. In addition, several cardiovascular risk factors can be modified in the process. The multicenter RCT (LookAHEAD) aimed to compare the effects of intensive lifestyle intervention (ILI) on the incidence of major CVD events among individuals with T2DM. ${ }^{26}$ The 5,145 overweight and obese individuals, average age 58.7 years, were randomized to ILI ( $7 \%$ weight loss at 1 year, with reduced-calorie diet modification and $175 \mathrm{~min} /$ week of physical activity) or standard care (DM support and education) and were followed up for almost 10 years. The ILI group achieved and maintained significantly more weight loss $(8.6 \%$ versus $0.7 \%$ at 1 year; $6.0 \%$ versus $3.5 \%$ at the end of trial) and improvements in fitness compared with the controls. Over 4 years of follow up, CVD risk factors $\left(\mathrm{HbA}_{1 \mathrm{c}}\right.$, $\mathrm{BP}$, high-density lipoprotein cholesterol [HDL] and triglycerides) were also better controlled in the intervention arm. However, these beneficial effects waned with time, and there was a neutral effect on cardiovascular outcomes (hazard ratio $0.95 ; 95 \%$ confidence interval $0.83-1.09 ; P=0.51$ ). The medical management the patients received in routine care may have, in part, blunted the impact of the ILI. ${ }^{27}$ In spite of this, this trial provides sufficient evidence that lifestyle intervention safely modifies several CVD risk factors, while providing at least some modest cardiovascular benefit, among DM individuals.

From the Look AHEAD evidence, individuals with DM can aim for a clinically meaningful weight loss goal of $7 \%$ in 1 year, with a long-term goal of achieving a healthy BMI of $<25 \mathrm{~kg} /$ $\mathrm{m}^{2}$. Even if this is not achieved, the Look AHEAD trial showed the benefits of modest weight loss ( $8.6 \%$ at 1 year) even without achieving the target for normal BMI. Added benefits of weight loss will include improved insulin sensitivity and glucose control as well as improvement of other risk factors, if present, like BP and lipids. The dietician needs to provide the DM patient with individualized medical nutrition therapy, where the focus should be on meal planning and, perhaps, going out with a packed lunch to prevent making poor food choices while at work. Substitution of energy-dense foods with foods rich in fiber, like fruits, vegetables, and whole grains, and with low-glycemic index is appropriate. Specific, realistic ways to achieve physical activity targets within the constraints of the individual's job should be 
addressed. For instance, this may include taking brisk walks in 10-minute bouts spread through the day, to improve cardiorespiratory fitness. On weekends, they can attend a structured exercise class or gymnasium, where some resistance training to strengthen the large muscle groups can be incorporated.

In older patients with long-standing DM, insulin deficiency usually worsens; therefore, the goal of medical nutrition therapy is more glycemic and metabolic control than weight loss. ${ }^{28}$ The same general exercise recommendation applies, but emphasis should be placed on low-intensity activities initially, like walking. This forms the basis for future improvement, and engagement in physical activity improves fitness as well as a general sense of well-being.

If these lifestyle modification strategies are followed by DM individuals and their family members, the expected short-term benefits ${ }^{26}$ will include improved feeling of wellbeing, which can increase self-efficacy and motivation; weight loss; good glycemic control; and metabolic control of lipids and BP. Expected longer-term benefits ${ }^{22,27}$ include reduced risk of developing DM in those without DM, as well as a reduction in the risk of microvascular complications and overall improved quality of life in those with DM.

Lifestyle strategies are cost effective, at least in delaying the onset of DM. This was demonstrated in a subgroup analysis of the DPP study that found that lifestyle intervention cost less than metformin in delaying the onset of one case of DM over 3 years. ${ }^{29}$ Lifestyle strategies, unlike pharmacotherapy, are not limited by side effects and tolerability (Table 2). Transient gastrointestinal disturbances and muscle aches may follow initiation of a new dietary and exercise regimen, respectively. In contrast to medications, which typically address only one risk factor, lifestyle modification simultaneously addresses obesity, glycemic control, BP, and lipid abnormalities. A key limitation of lifestyle strategies is that the changes shown to be efficacious in controlled clinical trials are difficult to initiate and sustain in real-life settings. Therefore, additional support may be required to assist the DM individual and his/her family members achieve their respective goals. This may involve referral to a structured patient education program, where available. In terms of physical activity targets, a simple tool, like a pedometer, can be utilized to motivate a gradual increase in movement up to at least 10,000 steps a day. Furthermore, behavioral strategies, such as stress management and self-monitoring of food and exercise can be instituted. In women in the DPP with a history of GDM, metformin and intensive lifestyle modification led to an equivalent $50 \%$ reduction in the risk of DM. Metformin therefore might reasonably be recommended, if risk for T2DM is still high after implementing lifestyle changes. ${ }^{30}$ Success should be monitored during follow-up visits, subjectively and objectively, as shown in Table 3.

\section{Evidenced-based medical management (pharmacotherapy)}

The aim of pharmacotherapy is to maintain stable concentrations of plasma glucose and to delay or prevent the onset of

Table 2 Effectiveness, advantages, and disadvantages of the various strategies employed in the management of DM

\begin{tabular}{|c|c|c|c|}
\hline Intervention & $\begin{array}{l}\text { Effectiveness } \\
\text { (\% Decrease in } \\
\left.\text { HbA }_{\text {IC }}\right)\end{array}$ & Advantages & Disadvantages \\
\hline $\begin{array}{l}\text { Lifestyle changes to decrease } \\
\text { weight and increase activity }\end{array}$ & $1.0-2.0$ & $\begin{array}{l}\text { Broad benefits, as outlined } \\
\text { in the text }\end{array}$ & Transient Gl and musculoskeletal discomfort \\
\hline Insulin & $1.5-3.5$ & $\begin{array}{l}\text { No dose limit, rapidly effective, } \\
\text { improves lipid profile }\end{array}$ & $\begin{array}{l}\text { One to four injections daily, monitoring, weight gain, hypoglycemia, } \\
\text { analogues are expensive }\end{array}$ \\
\hline Metformin & $1.0-2.0$ & $\begin{array}{l}\text { Weight neutral, low } \\
\text { hypoglycemia risk }\end{array}$ & $\begin{array}{l}\text { Gl side effects, lactic acidosis (rare), contraindicated with renal } \\
\text { insufficiency }\end{array}$ \\
\hline Sulfonylureas & $1.0-2.0$ & Rapidly effective & $\begin{array}{l}\text { Weight gain, hypoglycemia (especially with glibenclamide or } \\
\text { chlorpropamide) }\end{array}$ \\
\hline Thiazolidinediones & $0.5-1.4$ & $\begin{array}{l}\text { Improved lipid profile } \\
\text { (pioglitazone) }\end{array}$ & $\begin{array}{l}\text { Fluid retention, congestive heart failure, weight gain, bone fractures, } \\
\text { expensive }\end{array}$ \\
\hline DPP-4 inhibitors & $0.5-0.8$ & Weight-neutral & Long-term safety not established, expensive \\
\hline GLP-I analogs & $0.5-1.0$ & Weight loss & $\begin{array}{l}\text { Given by injection, frequent GI side effects, long-term safety not } \\
\text { established, expensive }\end{array}$ \\
\hline$\alpha$-glucosidase inhibitors & $0.5-0.8$ & Weight-neutral & Frequent GI side effects, three times per day dosing, expensive \\
\hline Glinides & $0.5-1.5$ & Rapidly effective & Weight gain, three times per day dosing, hypoglycemia, expensive \\
\hline Amylin analogs & $0.5-1.0$ & Weight loss & $\begin{array}{l}\text { Three injections daily, frequent GI side effects, long-term safety } \\
\text { not established, expensive }\end{array}$ \\
\hline
\end{tabular}

Note: Copyright (C) 2012. American Diabetes Association. Reproduced from Inzucchi SE, Bergenstal RM, Buse JB et al. American Diabetes Association (ADA); European Association for the Study of Diabetes (EASD). Management of hyperglycemia in type 2 diabetes: a patient-centered approach: position statement of the American Diabetes Association (ADA) and the European Association for the Study of Diabetes (EASD). Diabetes Care. 20I2;35(6):1364-1379.14

Abbreviations: DM, diabetes mellitus; DPP-4, dipeptidyl peptidase-4; GI, gastrointestinal; GLP-I, glucagon-like peptide- I; HbA ${ }_{\text {Ic' }}$ glycated hemoglobin. 
Table 3 Methods to monitor success of advice given

Self-regulation techniques

- Self-weighing, waist circumference measurements, or both

- The level of attendance to the clinic can be used as an indicator of commitment

Objective methods

- Changes in the amount of moderate to vigorous physical activity undertaken, assessed with exercise questionnaires

- Changes in dietary intake, monitored with food records

- Changes in weight, waist circumference, or BMI

- Changes in the fasting plasma glucose or $\mathrm{HbA}_{\mathrm{Ic}}$ will be used to monitor glycemic control

Note: Data taken from the 2012 NICE guidelines. ${ }^{30}$

Abbreviations: BMI, body mass index; $\mathrm{HbA}_{\mathrm{lc}}$, glycated hemoglobin; NICE, National Institute for Health and Care Excellence.

DM complications (especially microvascular complications), while not compromising on the quality of life of the patient. The choice of glucose-lowering medication depends, among other factors, on DM duration, level of glycemia, cost, and patient preference. ${ }^{14}$ The available drugs target different points in the pathogenetic pathway and have different effects on the metabolic profile as well as different side effects, but all lower blood glucose. However, their effects on macrovascular outcomes are not consistent. ${ }^{31}$ The benefits of metformin on cardiovascular and mortality outcomes in the UK Prospective Diabetes Study (UKPDS) study formed the basis of its emergence as the drug of first choice for lowering glucose in T2DM..$^{32}$ Thiazolidinediones are effective in lowering glucose as well as in reducing the incidence of T2DM but nonetheless have mixed data regarding their effects on CVD. While pioglitazone reduced the risk of stroke, myocardial infarction, and death by $16 \%$ in one RCT, another meta-analysis showed that rosiglitazone increased the risk of myocardial infarction by $30 \%-40 \% .33,34$

As with any pharmacotherapy, side effects occur, eg, weight gain, hypoglycemia, gastrointestinal discomfort, and fluid retention (Table 2). In addition, adherence to pharmacotherapy is influenced by several factors, including patient understanding of the medication benefits, and the complexity of the regimen. Poor adherence may thus limit the effectiveness of this strategy. ${ }^{35}$

\section{Individualizing glycemic targets}

Glycemic control is vital to the management of T2DM as glucotoxicity worsens beta-cell dysfunction, with consequent disease progression and onset of complications. ${ }^{36}$ Tight glycemic control is associated with lower risk of predominantly microvascular complications. ${ }^{37}$ With regards to cardiovascular outcomes, it appears that intensive glycemic control early on in the disease process confers modest benefit, while it is potentially harmful in patients with long-standing disease and other comorbidities.

The Action in Diabetes and Vascular Disease: Preterax and Diamicron Modified Release Controlled Evaluation (ADVANCE) trial, the Action to Control Cardiovascular Risk in Diabetes (ACCORD) trial, and the Veterans Administration Diabetes Trial (VADT) variously tested the effects of intensive glycemic control compared with conventional care on macrovascular end points. ${ }^{38-40}$ Though they all achieved significantly better glycemic control $\left(\mathrm{HbA}_{1 \mathrm{c}} 6.5 \%\right.$ versus $7.3 \% ; 6.4 \%$ versus $7.5 \%$; and $6.9 \%$ versus $8.4 \%$, respectively), they failed to show significant benefit, and in the ACCORD trial, there was excessive mortality (mostly cardiovascular) in the intervention arm, necessitating its early discontinuation. The patients in these trials were mostly middle aged and older, with long duration of DM and high CVD risk. The evidence from these trials would therefore not to support intensive glycemic control in an elderly patient because with long-standing T2DM, there is likely to be hypoglycemic unawareness, with consequent risks of severe hypoglycemic events. In addition, advanced age increases a person's risk for falls and fractures related to underlying osteoporosis, especially in women. This may be worsened by hypoglycemic spells. Aggressive therapy and tight glycemic control may do more harm than good, therefore looser $\mathrm{HbA}_{1 \mathrm{c}}$ targets $(<7.5 \%-8 \%)$ may be acceptable for such individuals. Regardless, the individual should be actively involved in the decision about their glycemic control. In a long-standing DM patient, the natural history of T2DM with progressive betacell failure results in the eventual necessity of insulin therapy. It can be challenging for a patient to accept the initiation of insulin therapy, so in administering DSME, the necessity for insulin treatment has to be explained, emphasizing that it does not indicate a "failure" on the part of the patient or the management team. A simplified regimen (eg, basal insulin plus metformin) can be used initially in concordance with self-monitoring of blood glucose. ${ }^{41}$ It is essential to educate the patient and their family to recognize early signs of hypoglycemia and the appropriate actions to take. All treatment decisions will depend on how far from the $\mathrm{HbA}_{1 \mathrm{c}}$ target the patient is. Sulphonylureas are a well-established class of glucose-lowering agents that act by closing adenosine triphosphate (ATP)-sensitive potassium channels on beta-cells and stimulate insulin release. Beta-cell exhaustion is likely to be the predominant pathogenetic mechanism in long-standing DM, and sulphonylureas accelerate beta cell exhaustion. ${ }^{42}$ They are cheap but also cause weight gain and hypoglycemia. ${ }^{14}$ Thiazolidinediones increase insulin sensitivity and reduce 
glucose output from the liver by activating peroxisome proliferator-activated receptor gamma (PPAR- $\gamma$ ). They do not cause hypoglycemia but have been associated with weight gain, heart failure, and bone fractures. ${ }^{43}$ Pioglitazone, which is currently the main form available, has been linked with bladder cancer. ${ }^{44}$ Incretin-based therapies (dipeptidyl peptidase-4 [DDP4] inhibitors and glucagon-like peptide-1 [GLP-1] agonists) enhance glucose-dependent insulin secretion in addition to suppressing glucagon secretion. In this way, glycemic control is improved with a low risk of hypoglycemia. ${ }^{45}$ They may be an alternative to insulin therapy; however, their use is limited by their high cost, amongst other factors. ${ }^{46}$

In contrast a younger, more recently diagnosed individual who has no history of significant CVD would require a different approach. If motivated, he/she will benefit from tighter glycemic control $\left(\mathrm{HbA}_{1 \mathrm{c}} 6 \%-6.5 \%\right)$. The UKPDS, a landmark $\mathrm{RCT}$, aimed to determine whether intensive glycemic control (fasting plasma glucose [FPG] $<6 \mathrm{mmol} / \mathrm{L}$ with sulphonylurea, insulin, or metformin if obese) reduced the risk of microvascular and macrovascular complications in newly diagnosed T2DM patients compared with conventional treatment (dietary therapy to maintain $\mathrm{FPG}<15 \mathrm{mmol} / \mathrm{L}$ ). ${ }^{32}$ The 4,209 participants, average age of 54 years, were randomized to the two groups, and over a 10 -year period, $\mathrm{HbA}_{1 \mathrm{c}}$ was $7 \%$ in the intensive-therapy group and $7.9 \%$ in the conventionaltherapy group. There was a significant $25 \%$ risk reduction in microvascular complications and a nonsignificant $16 \%$ risk reduction for myocardial infarction in the sulphonylureainsulin group $(P=0.052)$. However, over time, significant reductions in macrovascular complications emerged. The subgroup that was randomized to metformin (median dose $2,550 \mathrm{mg}$ ) achieved $0.6 \%$ lower $\mathrm{HbA}_{\mathrm{lc}}$ compared with the conventionally treated arm. This translated to a $39 \%$ reduction in the risk of myocardial infarction $(P=0.001)$, and $36 \%$ reduction in all-cause mortality $(P=0.01)$ that persisted for a decade postintervention. This is what has become known as the "legacy effect" ${ }^{37}$ In a reasonably healthy, recently diagnosed T2DM patient, the early cardiovascular benefit demonstrated with metformin in the UKPDS makes this a good first drug of choice. It acts by activating adenine monophosphate (AMP) kinase, suppressing hepatic gluconeogenesis and glycogenolysis, while increasing peripheral sensitivity to insulin. ${ }^{47}$ There is extensive experience with its use and it is weight-neutral, with a low risk for hypoglycemia. A tolerable low dose can be initiated and up-titrated to the higher doses used in the UKPDS. Moreover, evidence from a meta-analysis of seven double-blinded RCTs showed greater $\mathrm{HbA}_{1 \mathrm{c}}$ reduction with 2,000 $\mathrm{mg}$ versus 1,000-1,500 mg daily, without significant additional side effects. ${ }^{48}$ As T2DM is progressive, the patient will need additional therapy to control glycemia in the future, and they thus need to be advised accordingly, in order to manage their expectations. Glycemic control should be monitored with $\mathrm{HbA}_{1 \mathrm{c}}$ every 3 months, then biannually. If the target is not achieved, a second drug, like a sulphonylurea, can be added. It is associated with weight gain and hypoglycemia, thus a DPP4 inhibitor or GLP-1 receptor agonists may be the preferred second-line agents. ${ }^{14}$ However, every treatment decision should be carried out with the patient actively involved.

\section{Cardiovascular disease prevention}

Putting all this evidence together, a meta-analysis of the four RCTs (UKPDS, ACCORD, ADVANCE, and VADT) demonstrated that intensive glycemic control reduced the risk for nonfatal myocardial infarction by $14 \%$ ( 0.86 incidence rate ratio; $95 \%$ confidence interval $0.77-0.97 ; P=0.015)$ but did not affect total mortality or nonfatal stroke. ${ }^{49}$ However, the risks associated with intensive control include weight gain, hypoglycemia, and higher mortality rate. The current standard of care recommends individualizing glycemic targets based on patient characteristics, such as the duration of DM, risk of complications, age/life expectancy, comorbid conditions, known CVD, hypoglycemia unawareness, and individual patient preferences. ${ }^{14}$

Beyond glycemic control alone, CVD risk reduction requires a multifactorial approach that addresses $\mathrm{BP}$ and lipids also. The Steno-2 Study demonstrated the value of such an approach for comprehensive CVD risk reduction, utilizing behavior modification plus stepwise treatment of hyperglycemia, hyperlipidemia, and hypertension, in high-risk T2DM patients..$^{50}$ One hundred and sixty patients randomized to multidisciplinary intervention or usual care, were followed up for the primary end point, which was cardiovascular death and nonfatal events. Those in the intervention arm achieved lower levels of several risk factors and reduced risk of microvascular complications compared with patients receiving usual care. They also had a 50\% relative risk reduction in cardiovascular events. Five and a half years after the end of the trial, follow up showed that they had a $20 \%$ and $13 \%$ absolute risk reduction for all-cause mortality and cardiovascular death, respectively compared with those in standard care. ${ }^{51}$

A meta-analysis of statin therapy in DM patients showed that $1 \mathrm{mmol} / \mathrm{L}$ reduction in low-density lipoprotein (LDL) cholesterol reduced the 5-year incidence of major vascular events by about a fifth, irrespective of baseline cholesterol 
levels or comorbidities. ${ }^{52}$ The revised 2013 American College of Cardiology/American Heart Association guidelines use a new risk algorithm to guide statin therapy. Individuals with a calculated 10-year risk of "hard" atherosclerotic events of $\geq 7.5 \%$ qualify to receive statins.${ }^{53}$ Following these guidelines, most adult (40-75 years of age) patients with DM, will require statins, the intensity of which will be determined by their predicted 10-year risk. If the risk exceeds 7.5\%, they will require high-intensity statin treatment, to lower LDL by $50 \%$. If the risk is $<7.5 \%$, they will require a moderate-intensity statin, to lower LDL by $30 \%-50 \%$. The use of statins in these different groups has been shown to significantly lower the risk for cardiovascular events. However, it is important to note that the key drivers to high risk for cardiovascular events remain age, BP, and cigarette smoking, therefore smoking cessation and the lowering of BP cannot be overemphasized. In DM, the use of an angiotensin converting enzyme inhibitor as a first line BP-lowering agent is recommended. ${ }^{54}$

\section{The necessity for holistic care}

Due to the complexity of this disease, all aspects of its management need to be addressed in a complementary fashion incorporating treatment of acute complications while preventing long-term complications. In Nigeria, the clinical practice guidelines for the management of DM provide well-defined goals for the management of glycemia and other risk factors in DM. ${ }^{55}$ Despite this, the management and achievement of these goals remains a significant challenge. ${ }^{56-58} \mathrm{DM}$ care providers are virtually unavailable in the communities, and DM is managed mostly in the context of tertiary care settings. The drawbacks of this includes poor access to the hospitals by patients who may have to travel long distances, limited time available for the doctor to consult, paucity of DM educators, and fragmented DM care, ie, lack of DM care teams, as outlined in Table 1. The lack of DM educators hampers efficient delivery of DSME and techniques. The lack of integrated teams causes a reactive rather than a proactive approach. For instance, ophthalmologists or podiatrists review patients only when they get eye or foot problems. Chronic disease management programs regarding DM have been implemented with varying degrees of success in areas around the world. The Diabetes Education Engagement Program in the United States is a patient-centered collaborative care model promoting patient engagement, patient activation, and patient self-management, with the goal of improving outcomes in adult patients with T2DM. One year after implementation, the program was shown to result in fewer Emergency Room visits and an increase in the percentage of T2DM patients who attained the recommended $\mathrm{HbA}_{1 \mathrm{c}}$, BP, and lipid goals. ${ }^{59}$ Similarly, in Germany, there is a nationwide disease management program for DM that is based in primary care practice and is physician-led. It takes advantage of the physicians' personal relationships with patients to promote adherence to treatment goals and self-management. Compared with usual care, the overall mortality for patients, and drug and hospital costs were all significantly lower for patients who participated in the program after 4 years of follow up. ${ }^{60}$

These programs, while effective, are based in developed countries with well-developed health systems, national health insurance schemes, and reliable patient databases. Thus, these may not be applicable in countries like Nigeria. Nevertheless, in attempting to provide holistic care to Nigerian DM patients, the Diabetes Association of Nigeria is currently involved in rolling out DM education programs in communities, focused on training community health workers and DM educators. Complementary and alternative medicine use is highly prevalent among Nigerian DM patients, as are religious practices, such as faith healing. ${ }^{61}$ As a result, the DM programs in Nigeria try to adopt the principles of education and psychosocial support, integrating the sociocultural and religious heritage of the populace and involving religious leaders and traditional healers. This is aimed at empowering individuals to take charge of their DM and achieve the desired health outcomes. ${ }^{56}$

\section{Conclusion}

DM is a major risk factor for CVD, and its management is complex, requiring a patient-centered, multifactorial approach, starting with DSME. Lifestyle modification effectively prevents or delays the onset of T2DM in people at risk and, in combination with pharmacotherapy, is the foundation of care in those who already have the condition. Early intensive control of glucose and other risk factors delays the progression and onset of long-term complications; however, targets need to be individualized. The benefits, effectiveness, and disadvantages of evidence-based management strategies should be considered in the context of the individual's characteristics, and decisions regarding their use should be made with the individual. Achieving the set goals will ultimately improve long-term outcomes.

\section{Disclosure}

The authors declare no conflicts of interest in this work. 


\section{References}

1. Hex N, Bartlett C, Wright D, Taylor M, Varley D. Estimating the current and future costs of Type 1 and Type 2 diabetes in the UK, including direct health costs and indirect societal and productivity costs. Diabet Med. 2012;29(7):855-862.

2. Fonseca VA. Defining and characterizing the progression of type 2 diabetes. Diabetes Care. 2009;32 Suppl 2:S151-S156.

3. Shaw JE, Sicree RA, Zimmet PZ. Global estimates of the prevalence of diabetes for 2010 and 2030. Diabetes Res Clin Pract. 2010;87(1): 4-14.

4. Adibe MO, Aguwa CN, Ukwe CV. Cost-utility analysis of pharmaceutical care intervention versus usual care in management of Nigerian patients with type 2 diabetes. Value in Health Regional Issues. 2013;2(2):189-198.

5. worldbank.org [homepage on the Internet]. World DataBank: World development indicators. The World Bank; 2014 [cited December 26, 2013]. Available from: http://databank.worldbank.org/data/views/ variableselection/selectvariables.aspx? source=world-developmentindicators\#s_p. Accessed. March 26, 2014.

6. Buse JB, Ginsberg HN, Bakris GL, et al; American Heart Association; American Diabetes Association. Primary prevention of cardiovascular diseases in people with diabetes mellitus: a scientific statement from the American Heart Association and the American Diabetes Association. Diabetes Care. 2007;30(1):162-172.

7. Morrish NJ, Wang SL, Stevens LK, Fuller JH, Keen H. Mortality and causes of death in the WHO Multinational Study of Vascular Disease in Diabetes. Diabetologia. 2001;44 Supp1 2:S14-S21.

8. McLarty DG, Swai AB, Kitange HM, et al. Prevalence of diabetes and impaired glucose tolerance in rural Tanzania. Lancet. 1989;1(8643): 871-875.

9. Rodbard HW, Blonde L, Braithwaite SS, et al; AACE Diabetes Mellitus Clinical Practice Guidelines Task Force. American Association of Clinical Endocrinologists medical guidelines for clinical practice for the management of diabetes mellitus. Endocr Pract. 2007;13 Suppl 1:S1-S68.

10. Bellamy L, Casas JP, Hingorani AD, Williams D. Type 2 diabetes mellitus after gestational diabetes: a systematic review and meta-analysis. Lancet. 2009;373(9677):1773-1779.

11. American Diabetes Association. Standards of medical care in diabetes 2012. Diabetes Care. 2012;35 Suppl 1:S11-S63.

12. Schienkiewitz A, Schulze MB, Hoffmann K, Kroke A, Boeing H. Body mass index history and risk of type 2 diabetes: results from the European Prospective Investigation into Cancer and Nutrition (EPIC)-Potsdam Study. Am J Clin Nutr. 2006;84(2):427-433.

13. Jeon CY, Lokken RP, Hu FB, van Dam RM. Physical activity of moderate intensity and risk of type 2 diabetes: a systematic review. Diabetes Care. 2007;30(3):744-752.

14. Inzucchi SE, Bergenstal RM, Buse JB, et al; American Diabetes Association (ADA); European Association for the Study of Diabetes (EASD). Management of hyperglycemia in type 2 diabetes: a patient-centered approach: position statement of the American Diabetes Association (ADA) and the European Association for the Study of Diabetes (EASD). Diabetes Care. 2012;35(6):1364-1379.

15. Funnell MM, Brown TL, Childs BP, et al. National standards for diabetes self-management education. Diabetes Care. 2012; 35 Suppl 1:S101-S108.

16. Norris SL, Lau J, Smith SJ, Schmid CH, Engelgau MM. Self-management education for adults with type 2 diabetes: a meta-analysis of the effect on glycemic control. Diabetes Care. 2002;25(7):1159-1171.

17. Davies MJ, Heller S, Skinner TC, et al; Diabetes Education and Self Management for Ongoing and Newly Diagnosed Collaborative. Effectiveness of the diabetes education and self management for ongoing and newly diagnosed (DESMOND) programme for people with newly diagnosed type 2 diabetes: cluster randomised controlled trial. $B M J$. 2008;336(7642):491-495.

18. Jennings A, Mead A, Jones J, Holden A, Connolly S. Preventive Cardiology: A Practical Manual. Oxford: Oxford University Press 2009.
19. American Diabetes Association. Gestational diabetes mellitus. Diabetes Care. 2004;27 Suppl 1:S88-S90.

20. Tuomilehto J, Lindström J, Eriksson JG, et al; Finnish Diabetes Prevention Study Group. Prevention of type 2 diabetes mellitus by changes in lifestyle among subjects with impaired glucose tolerance. N Engl J Med. 2001;344(18):1343-1350.

21. Ramachandran A, Snehalatha C, Mary S, Mukesh B, Bhaskar AD, Vijay V; Indian Diabetes Prevention Programme (IDPP). The Indian Diabetes Prevention Programme shows that lifestyle modification and metformin prevent type 2 diabetes in Asian Indian subjects with impaired glucose tolerance (IDPP-1). Diabetologia. 2006;49(2):289-297.

22. Knowler WC, Barrett-Connor E, Fowler SE, et al; Diabetes Prevention Program Research Group. Reduction in the incidence of type 2 diabetes with lifestyle intervention or metformin. $N$ Engl J Med. 2002;346(6): 393-403.

23. Diabetes Prevention Program Research Group; Knowler WC, Fowler SE, Hamman RF, et al. 10-year follow-up of diabetes incidence and weight loss in the Diabetes Prevention Program Outcomes Study. Lancet. 2009;374(9702):1677-1686.

24. Chatterton H, Younger T, Fischer A, Khunti K; Programme Development Group. Risk identification and interventions to prevent type 2 diabetes in adults at high risk: summary of NICE guidance. $B M J$. 2012;345:e4624.

25. Hamman RF, Wing RR, Edelstein SL, et al. Effect of weight loss with lifestyle intervention on risk of diabetes. Diabetes Care. 2006;29(9): 2102-2107.

26. Look AHEAD Research Group; Wing RR. Long-term effects of a lifestyle intervention on weight and cardiovascular risk factors in individuals with type 2 diabetes mellitus: four-year results of the Look AHEAD trial. Arch Intern Med. 2010;170(17):1566-1575.

27. Wing RR, Bolin P, Brancati FL, et al; Look AHEAD Research Group. Cardiovascular effects of intensive lifestyle intervention in type 2 diabetes. N Engl J Med. 2013;369(2):145-154.

28. Franz MJ. The dilemma of weight loss in diabetes. Diabetes Spectr. 2007;20(3):133-136.

29. Diabetes Prevention Program Research Group. Within-trial costeffectiveness of lifestyle intervention or metformin for the primary prevention of type 2 diabetes. Diabetes Care. 2003;26(9):2518-2523.

30. National Institute for Health and Clinical Excellence (NICE). Preventing Type 2 Diabetes - Risk Identification and Interventions for Individuals at High Risk (PH38). London: National Institute for Health and Care Excellence; 2012. Available from: http://guidance.nice.org.uk/PH38 Accessed March 26, 2014

31. Brooks NA. Type 2 diabetes: lifestyle changes and drug treatment Virtual Mentor. 2009;11(3):237-241.

32. Stratton IM, Adler AI, Neil HA, et al. Association of glycaemia with macrovascular and microvascular complications of type 2 diabetes (UKPDS 35): prospective observational study. BMJ. 2000;321(7258): 405-412.

33. Dormandy JA, Charbonnel B, Eckland DJ, et al; PROactive investigators. Secondary prevention of macrovascular events in patients with type 2 diabetes in the PROactive Study (PROspective pioglitAzone Clinical Trial In macroVascular Events): a randomised controlled trial. Lancet. 2005;366(9493):1279-1289.

34. Singh S, Loke YK, Furberg CD. Long-term risk of cardiovascular events with rosiglitazone: a meta-analysis. JAMA. 2007;298(10):1189-1195.

35. Rubin RR. Adherence to pharmacologic therapy in patients with type 2 diabetes mellitus. Am J Med. 2005;118(Suppl 5A):27S-34S.

36. Harrison LB, Adams-Huet B, Raskin P, Lingvay I. $\beta$-cell function preservation after 3.5 years of intensive diabetes therapy. Diabetes Care. 2012;35(7):1406-1412.

37. Holman RR, Paul SK, Bethel MA, Matthews DR, Neil HA. 10-year follow-up of intensive glucose control in type 2 diabetes. $N$ Engl J Med. 2008;359(15):1577-1589.

38. ADVANCE Collaborative Group; Patel A, MacMahon S, Chalmers J, et al. Intensive blood glucose control and vascular outcomes in patients with type 2 diabetes. $N$ Engl J Med. 2008;358(24):2560-2572. 
39. Gerstein HC, Miller ME, Genuth S, et al; ACCORD Study Group. Longterm effects of intensive glucose lowering on cardiovascular outcomes. N Engl J Med. 2011;364(9):818-828.

40. Duckworth W, Abraira C, Moritz T, et al; VADT Investigators. Glucose control and vascular complications in veterans with type 2 diabetes. N Engl J Med. 2009;360(2):129-139.

41. Mooradian AD, Chehade JM. Diabetes mellitus in older adults. Am J Ther. 2012;19(2):145-159.

42. Wright A, Burden AC, Paisey RB, Cull CA, Holman RR; UK Prospective Diabetes Study Group. Sulfonylurea inadequacy: efficacy of addition of insulin over 6 years in patients with type 2 diabetes in the UK Prospective Diabetes Study (UKPDS 57). Diabetes Care. 2002;25(2):330-336.

43. Schwartz AV, Sellmeyer DE, Vittinghoff E, et al. Thiazolidinedione use and bone loss in older diabetic adults. J Clin Endocrinol Metab. 2006;91(9):3349-3354.

44. Hillaire-Buys D, Faillie JL, Montastruc JL. Pioglitazone and bladder cancer. Lancet. 2011;378(9802):1543-1544.

45. Kim W, Egan JM. The role of incretins in glucose homeostasis and diabetes treatment. Pharmacol Rev. 2008;60(4):470-512.

46. Nyenwe EA, Jerkins TW, Umpierrez GE, Kitabchi AE. Management of type 2 diabetes: evolving strategies for the treatment of patients with type 2 diabetes. Metabolism. 2011;60(1):1-23.

47. Goodarzi MO, Bryer-Ash M. Metformin revisited: re-evaluation of its properties and role in the pharmacopoeia of modern antidiabetic agents. Diabetes Obes Metab. 2005;7(6):654-665.

48. Hirst JA, Farmer AJ, Ali R, Roberts NW, Stevens RJ. Quantifying the effect of metformin treatment and dose on glycemic control. Diabetes Care. 2012;35(2):446-454.

49. Marso SP, Kennedy KF, House JA, McGuire DK. The effect of intensive glucose control on all-cause and cardiovascular mortality, myocardial infarction and stroke in persons with type 2 diabetes mellitus: a systematic review and meta-analysis. Diab Vasc Dis Res. 2010;7(2): 119-130.

50. Pedersen O, Gaede P. Intensified multifactorial intervention and cardiovascular outcome in type 2 diabetes: the Steno-2 study. Metabolism. 2003;52(8 Suppl 1):19-23.

51. Gaede P, Lund-Andersen H, Parving HH, Pedersen O. Effect of a multifactorial intervention on mortality in type 2 diabetes. N Engl J Med. 2008;358(6):580-591.

52. Kearney PM, Blackwell L, Collins R, et al; Cholesterol Treatment Trialists' (CTT) Collaborators. Efficacy of cholesterol-lowering therapy in 18,686 people with diabetes in 14 randomised trials of statins: a meta-analysis. Lancet. 2008;371(9607):117-125.
53. Stone NJ, Robinson J, Lichtenstein AH, et al. 2013 ACC/AHA Guideline on the treatment of blood cholesterol to reduce atherosclerotic cardiovascular risk in adults: A report of the American College of Cardiology/American Heart Association Task Force on Practice Guidelines. Circulation. Epub November 7, 2013.

54. Perk J, De Backer G, Gohlke H, et al; European Association for Cardiovascular Prevention and Rehabilitation (EACPR); ESC Committee for Practice Guidelines (CPG). European Guidelines on cardiovascular disease prevention in clinical practice (version 2012). The Fifth Joint Task Force of the European Society of Cardiology and Other Societies on Cardiovascular Disease Prevention in Clinical Practice (constituted by representatives of nine societies and by invited experts). Eur Heart J. 2012;33(13):1635-1701.

55. Chinenye S, Ofoegbu EN, Onyemelukwe GC, Uloko AE, Ogbera AO, editors. Clinical Practice Guidelines for Diabetes Management in Nigeria. 2nd edition. Port Harcourt: Diabetes Association of Nigeria; 2013.

56. Chinenye S, Ogbera AO. Socio-cultural aspects of diabetes mellitus in Nigeria. J Soc Health Diabetes. 2013;1(1):15-21

57. Uloko AE, Obegbu EN, Chinenye S, et al. Profile of Nigerians with diabetes mellitus - Diabcare Nigeria study group (2008): Results of a multicenter study. Indian J Endocrinol Metab. 2012;16(4):558-564.

58. Nwankwo CH, Nandy B, Nwankwo BO. Factors influencing diabetes management outcome among patients attending government health facilities in South East Nigeria. International Journal of Tropical Medicine. 2010;5(2):28-36.

59. Willover S. Apply holistic care collaboration to type 2 diabetes. Managed Healthcare Executive [serial on the Internet]. November 1, 2013 [cited March 4, 2014]:1-4. Available from: http://managedhealthcareexecutive. modernmedicine.com/managed-healthcare-executive/news/ apply-holistic-care-collaboration-type-2-diabetes. Accessed March 26, 2014.

60. Stock S, Drabik A, Büscher G, et al. German diabetes management programs improve quality of care and curb costs. Health Aff (Millwood). 2010;29(12):2197-2205.

61. Ogbera AO, Dada O, Adeyeye F, Jewo PI. Complementary and alternative medicine use in diabetes mellitus. West Afr J Med. 2010;29(3):158-162.

62. Rydén L, Standl E, Bartnik M, et al; Task Force on Diabetes and Cardiovascular Diseases of the European Society of Cardiology (ESC); European Association for the Study of Diabetes (EASD). Guidelines on diabetes, pre-diabetes, and cardiovascular diseases: executive summary. The Task Force on Diabetes and Cardiovascular Diseases of the European Society of Cardiology (ESC) and of the European Association for the Study of Diabetes (EASD). Eur Heart J. 2007;28(1):88-136.

Diabetes, Metabolic Syndrome and Obesity: Targets and Therapy

Dovepress

\section{Publish your work in this journal}

Diabetes, Metabolic Syndrome and Obesity: Targets and Therapy is an international, peer-reviewed open-access journal committed to the rapid publication of the latest laboratory and clinical findings in the fields of diabetes, metabolic syndrome and obesity research. Original research, review, case reports, hypothesis formation, expert opinion and commentaries are all considered for publication. The manuscript management system is completely online and includes a very quick and fair peer-review system, which is all easy to use. Visit http://www.dovepress.com/testimonials.php to read real quotes from published authors. 